УДК 621.38

А. О. Куцевол, магістр,

Ю. Г. Лега, д.m.н., професор,

О. С. Гавриш, к.ф.-м.н., дочент,

М. О. Багрій, магістр

Черкаський державний технологічний університет

б-р Шевченка, 460, Черкаси, 18006, Україна

\title{
ВИКОРИСТАННЯ СИСТЕМИ ТЕХНІЧНОГО ЗОРУ ДЛЯ АВТОМАТИЗАЦІЇ СОРТУВАННЯ ОВОЧІВ/ФРУКТІВ ЗА РОЗМІРОМ
}

Розроблено установку для сортування овочів/фруктів за розміром на базі системи технічного зору. Розробка дозволяе прискорити робочий процес по сортуванню овочів/фруктів $i$ точніше відбирати їх за розміром, базуючись на визначенні таких параметрів: висота, иирина, периметр та площа зображення вимірюваного об’єкта; коефіџієнт форми.

Ключові слова: автоматизована установка, технічний зір, цииррова обробка зображень, середовище LabVIEW, модуль Vision Assistant.

Вступ. Традиційно рослинництво є однією $з$ основних галузей народного господарства України. Ефективність вирощування продуктів рослинництва залежить від багатьох чинників, серед яких одне 3 основних місць посідає якість насіння. При великих об'ємах обробки посівного матеріалу виникає необхідність використання автоматизованих систем сортування (калібрування). Також актуальне сортування продуктів рослинництва, яке може передувати етапу збуту вирощеної продукції.

В останні роки цифрова обробка і цифровий аналіз зображень знаходять все ширше застосування в різних галузях науки і техніки, таких як: інтелектуальні робототехнічні комплекси, системи промислового контролю, системи управління рухомими апаратами, обробка даних дистанційного зондування, біомедичні дослідження, нові технології обробки документів і багато інших [1].

Проблематика технічного зору полягає в тому, що нині технічні можливості досягли такого рівня, що майже зрівнялися 3 можливостями людського ока, розширення багатьох сенсорів для отримання відеоінформації майже відповідає кількості елементів рогівки людського ока, а можливості ЕОМ і спеціальних процесорів близькі до характеристик «обчислювальних потужностей», використовуваних для обробки зображень у мозку. Тому цю систему все частіше починають використовувати для різного роду вимірювальної техніки [2].
Популярним середовищем, що грунтується на концепції віртуальних інструментів та системі віртуального зору, є NI LabVIEW (National Instruments Laboratory Virtual Instrument Engineering Workbench) [3-6]. У фундаментальній науці LabVIEW використовують такі передові центри, як CERN, Lawrence Livermore, Batelle, Oak Ridge, в інженерній практиці - об'єкти космічного, повітряного, надводного та підводного флотів, промислові підприємства.

Найбільш близькою за функціональними можливостями $є$ установка, описана в роботах $[7 ; 8]$, призначена для оцінювання якості інкубаційних яєць шляхом вимірювання їх геометричних розмірів і форми на базі системи технічного зору. В роботі [9] синтезовано автоматизовану установку в середовищі LabVIEW [10-13] для визначення геометричних розмірів бульб картоплі. Установки, описані в роботах [7-9], мають майже однакову будову, проте більша різноманітність форм і більший розкид геометричних розмірів бульб картоплі змушують проводити додаткові дослідження, спрямовані на отримання оптимального зображення за рахунок правильного вибору положення камери відносно вимірюваного об'єкта.

Постановка задачі. В роботі розробляється установка для обробки отриманого зображення, визначення параметрів виділеного об'єкта, аналізу та порівняння отриманих даних $з$ допустимими граничними значеннями і подальшим виведенням інформації на екран. 
Отримання зображення відбувається за допомогою веб-камери, далі за допомогою модуля Vision Assistant [4] відбувається обробка зображення та визначення геометричних параметрів основного об'єкта зображення. Для цього було розроблено відповідний алгоритм обробки та аналізу зображення.

Отримані вихідні дані обробляються і аналізуються розробленою блок-схемою, яка порівнює отримані параметри 3 нормованими та виводить всю інформацію на екран. Вся інформація в ході досліду заноситься до таб- лиці та автоматично виводиться в файл MS Excel.

Мета роботи полягає в розробці функціональної схеми установки, яка в автоматизованому режимі, з мінімальними затратами часу, визначає геометричні параметри зображення об'єкта та відбирає об'єкти за певними критеріями.

Результати роботи. Розроблено алгоритм обробки зображення (рис. 1), в модулі Vision Assistant він називається скриптом, скрипт містить десять блоків:

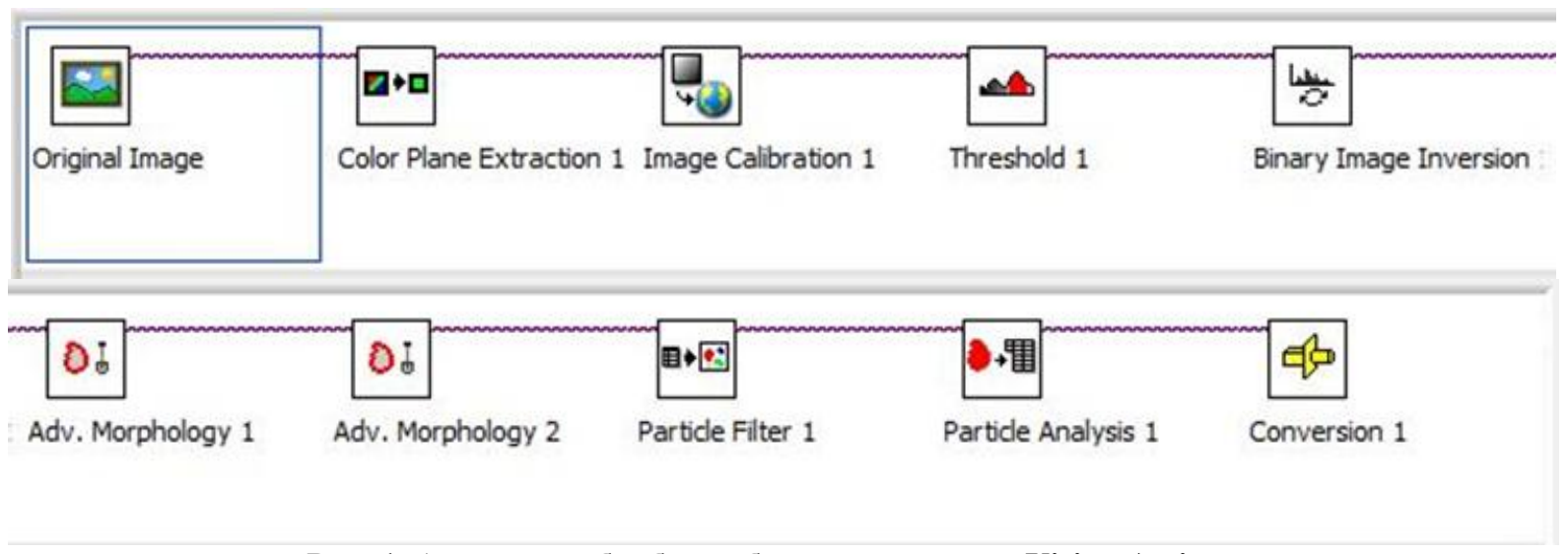

Рис. 1. Алгоритм обробки зображення модуля Vision Assistant

1) Original Image - оригінал зображення;

2) Color Plane Extraction - конвертація зображення в чорно-білу гамму;

3) Image Calibration - калібрування зображення;

4) Threshold - розділення зображення за градаціями сірого на підложку та власне зображення;

5) Binary Image Inversion - інвертування бінарного зображення;

6) Два блоки Advanced Morphology: перший блок відсікає частинки, що дотикаються до границі зображення, а другий - заповнює отвори у вже виділених об'єктах;

$7,8)$ Particle Filter - відбір частинок за певним принципом (наприклад видалення усіх частинок, що мають відношення поперечного розміру до поздовжнього, більше від заданого);

9) Particle Analysis - визначення геометричних параметрів виділеного об'єкта;

10) Conversion - конвертує зображення у вказаний тип зображення.

Кожен $з$ цих блоків має свої налаштування та функції.

Блок Original Image відображає оригінальне зображення, яке було завантажене в мо- дуль Vision Assistant. Цей блок відображається одразу після запуску модуля, тому він не потребує ніякого налаштування.

Блок Color Plane Extraction потрібен для того, щоб була можливою подальша обробка зображення. Оскільки не всі блоки в змозі працювати 3 кольоровими зображеннями, тому потрібно перетворити зображення 3 кольорового в чорно біле.

Блок Image Calibration [5] потрібен для того, щоб відкалібрувати зображення. Калібрування зображення необхідне для того, щоб знати, якою є реальна відстань між двома точками зображення. Для цього була використана звичайна лінійка, яку було сфотографовано i завантажено в модуль Vision Assistant. Таким чином було отримано дані, які визначали, що кількість пікселів n дорівнює певній відстані. Важливо, щоб розширення зображення досліджуваного об'єкта і розширення зображення лінійки були однаковими, інакше проводити подальші вимірювання буде неможливо.

Блок Threshold [2, с. 140] виконує бінаризацію зображення. Після цього значення кожного пікселя зображення стає рівним 0 (фон) або 1 (об’єкт) (рис. 2). 

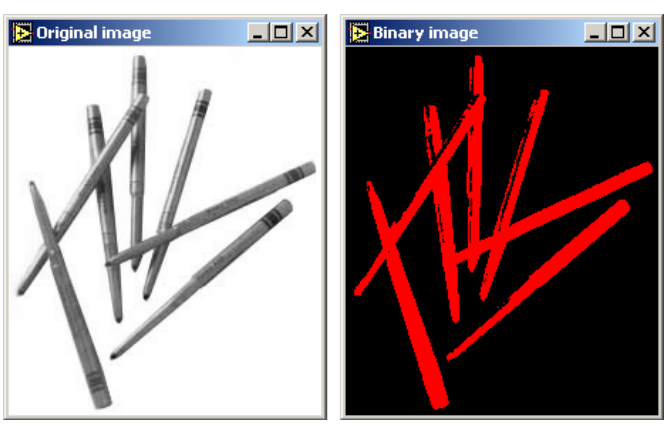

Рис. 2. Результат операції Threshold

Блок Binary Image Inversion інвертує результат бінаризації.

Блок Advanced Morphology відсікає зайві об'єкти, що дотикаються до границі об'єкта. Це потрібно, щоб вони не сприймалися як частина основного об'єкта і в подальшому не обчислювались їхні параметри. Також цей блок заповнює отвори в об'єкті, щоб таким чином запобігти збою в розрахунку параметрів.

Блок Particle Filter виконує відсікання частинок, які не видалились після відсікання зайвих частинок у блоці Advanced Morphology, оскільки ті булі завеликими чи знаходились далеко від границі об'єкта і розпізналися як основний об'єкт. Видалення зайвих частинок відбувається за певним принципом, наприклад, якщо дано об'єкт, що має певну висоту і ширину, то всі інші об'єкти, які менші за розмірами, будуть видалятись. Блок Particle Analysis виконує аналіз об'єкта, визначає його геометричні параметри та виводить у табличний ряд. Цей блок налаштовується залежно від того, які параметри потрібно визначити і в яких одиницях виміру.

Блок Conversion перетворює зображення у вказаний тип. Це необхідно для того, щоб після всіх маніпуляцій із зображенням воно відображалось на виході в блоці Image Out. Якщо не поставити цей блок, то на виведеному зображенні буде видно тільки чорний екран.

Протестувавши алгоритм обробки зображення, також було розроблено блок-схему обробки та аналізу отриманих даних (рис. 3). Найважливішими блоками схеми $є$ блоки Vision Acquisition i Vision Assistant (табл. 1). Блок Vision Acquisition виконує захоплення зображення, його можна налаштувати на різні режими отримання зображення.

За допомогою певних налаштувань можна зробити одиничний знімок, безперервно виконувати збір даних з камери чи задати визначену кількість знімків, що виконує камера.

Блок Vision Assistant є простим і зручним засобом, за допомогою якого можна швидко здійснити будь-які необхідні дії над вихідним зображенням.

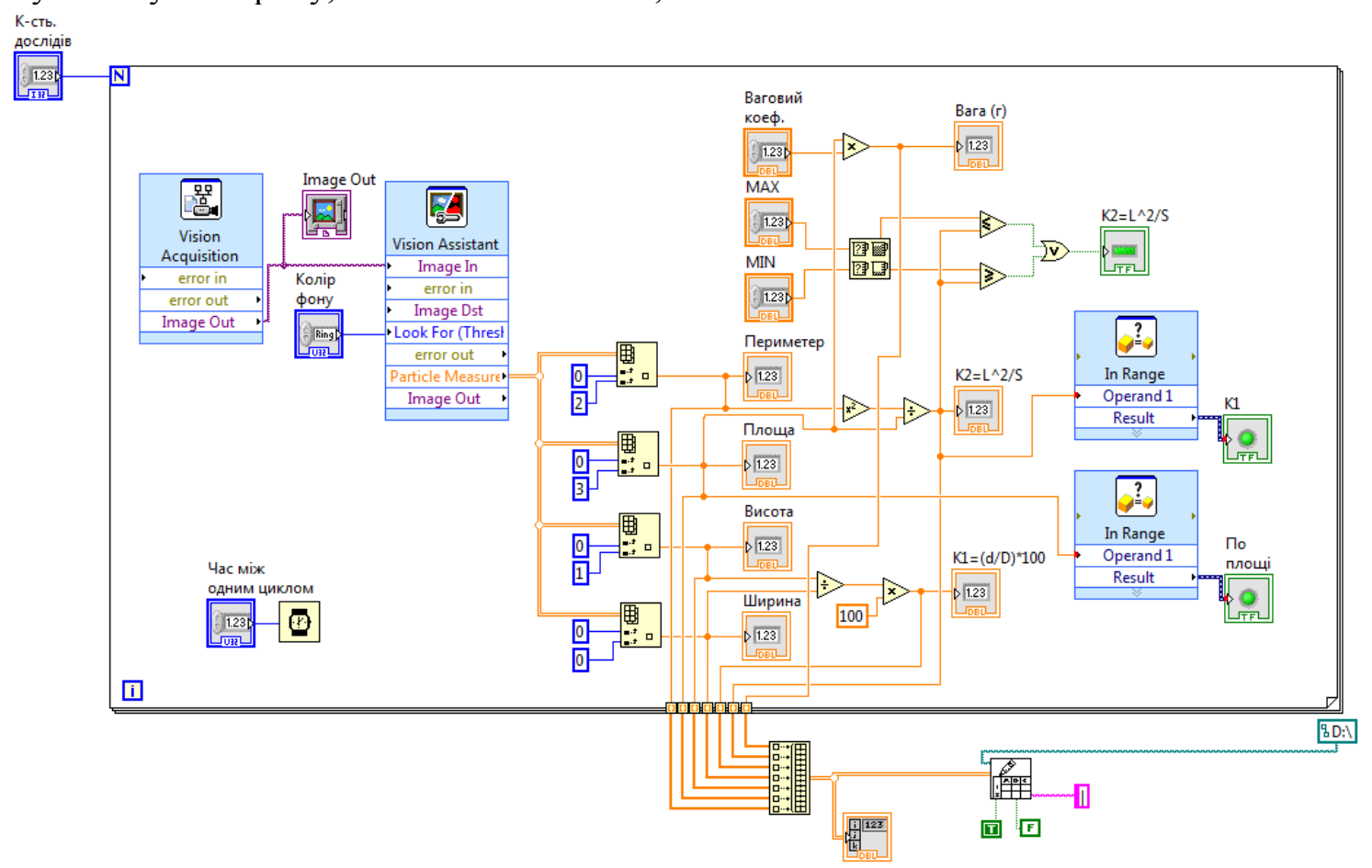

Рис. 3. Функціональна блок-схема установки 
Для виведення отриманих даних 3 модуля Vision Assistant було підключено блоки Index Array, які виділяють певні значення 3 таблиці отриманих геометричних параметрів. Ці параметри в подальшому використовуються для розрахунку коефіцієнта форми об'єкта. Для розрахунку коефіцієнта форми [8] також використовувались відповідні блоки математичних операцій.

Далі ці значення потрапляють до компаратора, який відбирає дані в заданому діапазоні і виводить на індикатор інформацію про відповідність певному критерію. Наприклад, якщо коефіцієнт форми дорівнює певній константі, то всі значення, що більші або менші за задане, будуть відкидатись, а індикатор буде загорятись, якщо отримані дані не будуть відповідати нормі.

Проведені вимірювання та розрахунки будуть виводитись на екран у вигляді таблиці завдяки блоку Array, а також переводитись у табличний файл MS Excel завдяки блоку Write To Spreadsheet File.vi.

Таблиця 1

Опис елементів блок-діаграми

\begin{tabular}{|c|c|c|}
\hline № & Елемент & Опис \\
\hline 1 & 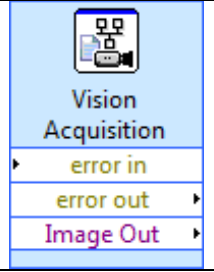 & $\begin{array}{l}\text { Захоплення зобра- } \\
\text { ження, налаштуван- } \\
\text { ня контрастності, } \\
\text { час захоплення, } \\
\text { розширення зобра- } \\
\text { ження }\end{array}$ \\
\hline 2 & \begin{tabular}{|l|} 
\\
Vision Assistant \\
Image In \\
error in \\
Image Dst \\
error out \\
Particle Measure \\
Image Out \\
\end{tabular} & $\begin{array}{l}\text { Модуль Vision As- } \\
\text { sistant для виділення } \\
\text { зображення від фо- } \\
\text { ну, переведення в } \\
\text { монохромний вид } \\
\text { зображення, каліб- } \\
\text { рування та вимірю- } \\
\text { вання розмірів } \\
\text { об'єкта в метричній } \\
\text { системі }\end{array}$ \\
\hline 3 & 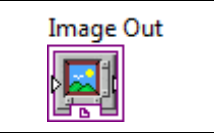 & $\begin{array}{l}\text { Індикатор для виве- } \\
\text { дення захопленого } \\
\text { зображення }\end{array}$ \\
\hline 4 & 㫼 & $\begin{array}{l}\text { Бібліотека для виді- } \\
\text { лення з таблиці } \\
\text { отриманих геомет- } \\
\text { ричних параметрів } \\
\text { для подальших роз- } \\
\text { рахунків }\end{array}$ \\
\hline 5 & & $\begin{array}{l}\text { Математичний еле- } \\
\text { мент піднесення до } \\
\text { степеня }\end{array}$ \\
\hline 6 & & $\begin{array}{l}\text { Математичний еле- } \\
\text { мент відношення }\end{array}$ \\
\hline
\end{tabular}

Для цієї установки також був розроблений інтерфейс програми (рис. 4). На рис. 4 позначено:

1) кількість дослідів;

2) час між одним циклом;

3) вибір кольору фону, на якому знаходиться об'єкт;

4) індикатор площі та коефіцієнта форми;

\begin{tabular}{|c|c|c|}
\hline 7 & $x$ & $\begin{array}{l}\text { Математичний еле- } \\
\text { мент множення }\end{array}$ \\
\hline 8 & 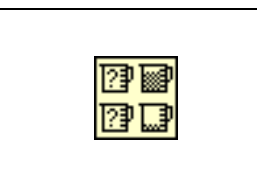 & $\begin{array}{l}\text { Бібліотека порівню- } \\
\text { вання за мінімаль- } \\
\text { ним і максимальним } \\
\text { значеннями }\end{array}$ \\
\hline 9 & 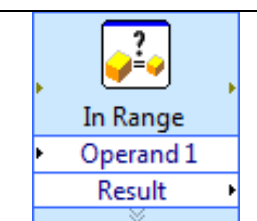 & $\begin{array}{l}\text { Компаратор для } \\
\text { отримання коефіці- } \\
\text { єнта форми в зада- } \\
\text { ному діапазоні }\end{array}$ \\
\hline 10 & 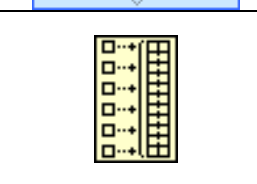 & $\begin{array}{l}\text { Бібліотека } \\
\text { об'єднання одинич- } \\
\text { них параметрів у } \\
\text { табличний ряд }\end{array}$ \\
\hline 11 & 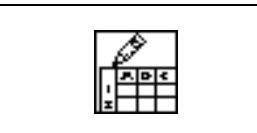 & $\begin{array}{ll}\text { Бібліотека } \\
\text { табличедачі } \\
\text { Excel }\end{array}$ \\
\hline 12 & 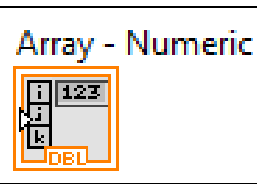 & 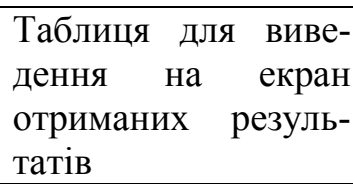 \\
\hline 13 & $\frac{1.23}{\sqrt{D E L}}$ & $\begin{array}{l}\text { Індикатор отрима- } \\
\text { них результатів }\end{array}$ \\
\hline 14 & 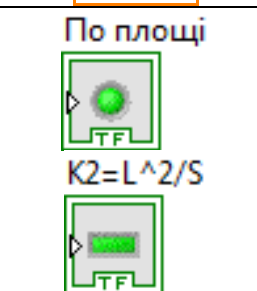 & Індикатор браку \\
\hline
\end{tabular}

5) індикатор браку за коефіцієнтом форми;

6) діапазон коефіцієнта форми;

7) ваговий коефіцієнт;

8) індикатор отриманих даних;

9) візуальне зображення об'єкта;

10) таблиця 3 загальними даними по кожному досліду. 


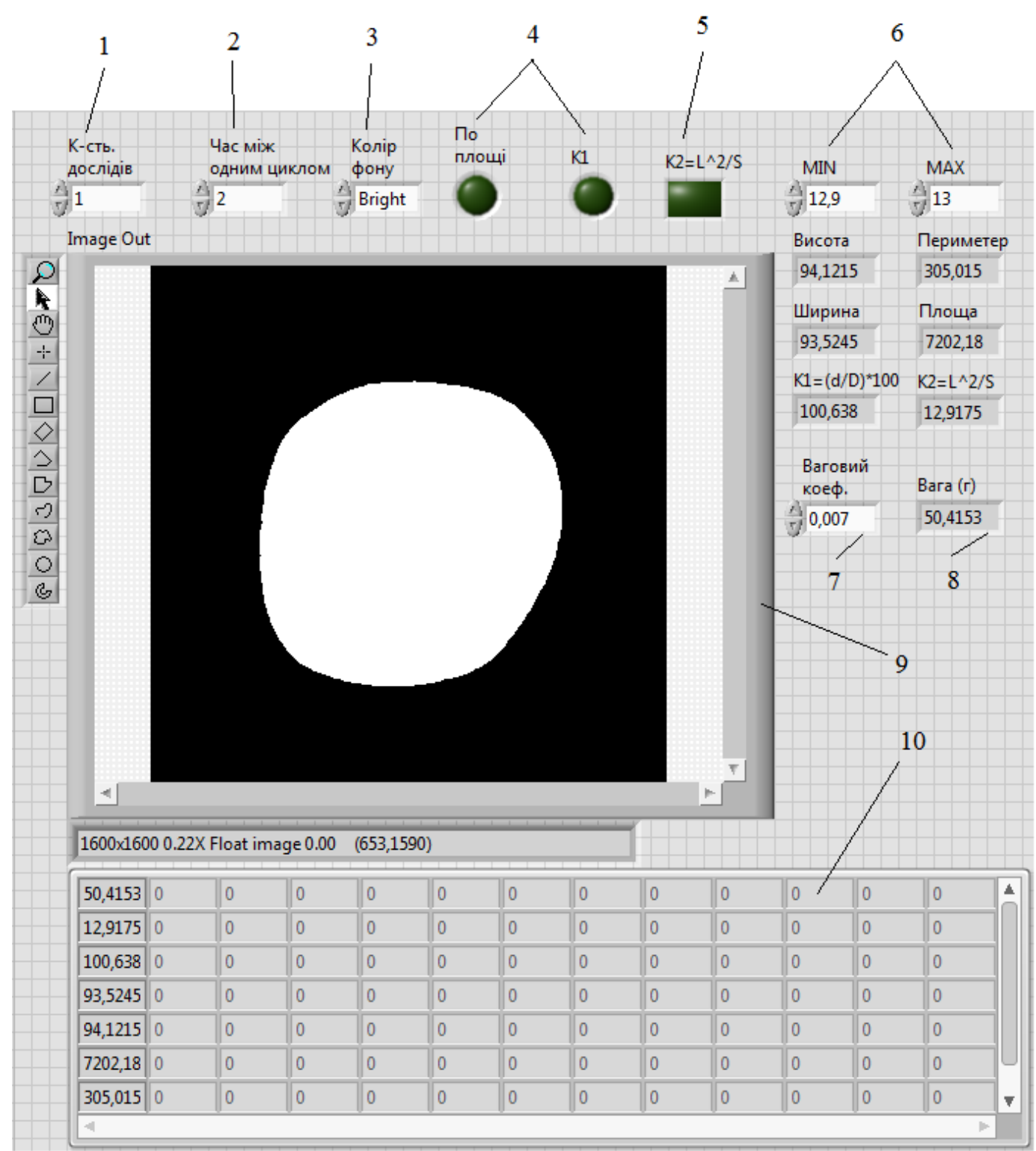

Рис. 4. Інтерфейс програми

Висновки. Використовуючи програмне забезпечення NI LabVIEW та додаткові бібліотеки і модулі, розроблено функціональну схему установки, яка дозволяє сортувати овочі/фрукти за розміром і формою. При використанні системи технічного зору для сортування продукції, крім геометричних розмірів, використовується коефіцієнт складності форми, який являє собою відношення квадрата периметра до площі i, очевидно, для різних овочів/фруктів має різні значення. Для овочів/фруктів «правильної» форми можна визначати їх вагу, оскільки вона корелює 3 їх площею, але для різних овочів/фруктів потрібно задавати свій ваговий коефіцієнт, який найпростіше визначати експериментально перед сортуванням партій продукції заданого виду. Використання автоматизованої установки дозволить підвищити продуктивність сортування у декілька разів порівняно з ручним методом і забезпечує більш високі точність $\mathrm{i}$ якість сортування, оскільки при комп'ютерній обробці зображень висуваються чіткі математичні критерії відбору.

\section{Список літератури}

1. Творошенко I. С. Конспект лекцій з дисципліни «Цифрова обробка зображень» для студентів 4 курсу денної форми навчання напряму 6.080101 - Геодезія, картографія та землеустрій; Харків. нац. ун-т 
міськ. госп-ва ім. О. М. Бекетова. Харків: ХНУМГ ім. О. М. Бекетова, 2017. 75 с.

2. Визильтер Ю. В., Желтов С. Ю., Князь В. А., Ходарев А. Н., Моржин А. В. Обработка и анализ цифровых изображений с примерами на LabVIEW IMAQ Vision. Москва: ДМК Пресс, 2007. 464 с.

3. Офіційний сайт National Instruments. URL: www.ni.com

4. NI Vision Development Module. URL: http://sine.ni.com/nips/cds/view/p/lang/ru/nid $/ 2881$.

5. NI Vision: Step 3: Develop Vision Script. URL: https://www.youtube.com/wat ch?v= LR33-W4Thww\&list=

PLgd8MjgDMLtdenvdHO14pt6v1OYAASuOd

6. NI Vision Builder Automated Inspection Dominos (Machine Vision Demo). URL: https://www.youtube.com/watch?v=e7QJLM vHE1 Y\&list=PLgd8MjgDMLtdenvdHOl4pt 6v1OYAASuOd\&index $=2$

7. Алиханов Дж., Молдажанов А., Шыныбай Ж., Цонев Р., Даскалов П. Метод оценки качеств инкубационных яиц путем определения их геометрических параметров. Научни трудове на русенския университет. 2012. Т. 51, серия 3.1. С. 182-187.

8. Алиханов Д. М., Молдажанов А. К. Установка для автоматизированного определения геометрических параметров яиц на базе системы технического зрения. Маchines, technologies, materials: sci. proceedings of the XI international congress. 2014. C. $37-40$.

9. Алиханов Д., Шыныбай Ж., Молдажанов А., Даскалов П. Результаты исследований автоматизированной установки для измерения геометрических параметров клубней картофеля на базе системы технического зрения. Agricultural machinery: sci. proceedings of the III international sci. and tech. conf. 2015. C. 41-44.

10. Суранов А. Я. LabVIEW 8.20: справочник по функциям. Москва: ДМК Пресс, 2007. $536 \mathrm{c}$.

11. Тревис Джеффри. LabVIEW для всех / пер. с англ. Клушин Н. А. Москва: ДМК Пресс; Прибор Комплект, 2005. 544 с.

12. Луценко Г. В. Методика створення модулів обробки експериментальних даних у середовищі LABVIEW. Вісник Черкаського національного університету. 2012. Вип. 12 (225). С. 61-67.
13. Воєводін С. Імітаційне моделювання й віртуальні вимірювання в лабораторному практикумі. Інформатика. 2010. № 41-43 (569-571). C. 3-17.

\section{References}

1. Tvoroshenko, I. S. (2017) Abstract of the lectures on discipline "Digital Image Processing" for students of the 4-year course of full-time study, direction 6.080101 - Geodesy, cartography and land management.; Kharkiv Nat. Un-ty of city households named by O. M. Beketov. Kharkiv: KhNUMG im. O. M. Beketov, 75 p. [in Ukrainian].

2. Vizilter, Yu. V., Zheltov, S. Yu., Knyaz, V. A., Khodarev, A. N., Morzhin, A. V. (2007) Processing and analysis of digital images with examples on LabVIEW IMAQ Vision. Moscow: DMK Press. 464 p. [in Russian].

3. National Instruments official website. URL: www.ni.com

4. NI Vision Development Module. URL: http://sine.ni.com/nips/cds/view/p/lang/en/nid/ 2881.

5. NI Vision: Step 3: Develop Vision Script [Electronic resource]. - Access mode https://www.youtube.com/watch?v=LR33W4Thww\&list=PLgd8MjgDMLtdenvdHOI4 pt6v1OYAASuOd.

6. NI Vision Builder Automated Inspection Dominos (Machine Vision Demo). URL: https://www.youtube.com/watch?v=e7QJLM vHE1Y\&list=PLgd8MjgDMLtdenvdHOl4pt 6v1OYAASuOd\&index $=2$

7. Alikhanov, J., Moldazhanov, A., Shynybye, J., Tsonev, R., Daskalov, P. (2012) The method for assessment of incubation eggs quality by determining their geometrical parameters. Nauchni trudove na rusenskiya universitet. Vol. 51, series 3.1, pp.182-187 [in Russian].

8. Alikhanov, J., Moldazhanov, A. (2014) Installation for automated determination of geometric parameters of egg-based machine vision system. Machines, technologies, materials: sci. proceedings of the XI international congress, pp. 37-40 [in Russian].

9. Alikhanov, J., Moldazhanov, A., Shynybye, J., Daskalov, P. (2015) Results of the research of automated installation for definition of geometrical parameters of potato tubers based on vision systems. Agricultural machi- 
nery: sci. proceedings of the III international sci. and tech. conf., pp. 41-44 [in Russian].

10. Suranov, A. Ya. (2007) LabVIEW 8.20: functional reference. Moscow: DMK Press, 536 p. [in Russian].

11. Travis, Jeffrey (2005) LabVIEW for everyone. Moscow: DMC Press; Pribor Komplekt, 544 p. [in Russian].
12. Lutsenko, G. V. (2012) Technique for creating modules for experimental data processing in LabVIEW environment. Visnyk Cherkaskoho natsionalnoho universytetu, iss. 12 (225), pp. 61-67 [in Ukrainian].

13. Voyevodin, S. (2010) Imitation modeling and virtual measurements in laboratory practice. Informatyka, No. 41-43 (569-571), pp. 3-17 [in Ukrainian].

\author{
A. O. Kutsevol, master \\ Yu. G. Lega, Dr.Tech.Sc., professor, \\ O. S. Havrysh, Ph.D., associate professor, \\ M. O. Bagrii, master \\ Cherkasy State Technological University \\ Shevchenko blvd, 460, Cherkasy, 18006, Ukraine

\section{THE USE OF A SYSTEM OF TECHNICAL VISION FOR AUTOMATION OF VEGETABLES/FRUITS SORTING BY SIZING}

In this work, a functional diagram for sizing of vegetables/fruits based on technical vision system using LabView and Vision Assistant environment has been developed. The developed installation allows to speed up the working process on vegetables/fruits sizing and to more accurately select them by size. This installation is intended to determine such parameters: height, width, perimeter and area of the image of the measured object; coefficient of form. All parameters are measured by contactless method, with further elaboration of the results of measurements in LabView environment, which allows to improve the quality of product sizing.

Keywords: automated installation, technical vision, digital image processing, LabVIEW environment, Vision Assistant module. 